\title{
Memorial de ida $i$ venida hasta Maka. La peregrinación de Omar Paton
}

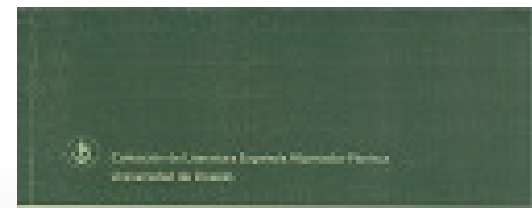

Merrorial de ida i menida hasta Hak

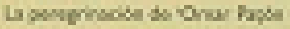

intmente

whersing
FICHA BIBLIOGRÁFICA

Pablo Roza Candás, Memorial de ida i venida hasta Maka. La peregrinación de Omar Paton. Oviedo, Servicio de Publicaciones de la Universidad de Oviedo, 2018, 482 págs. ISBN 978-84-16343-67-6

\section{María Jesús Fuente I Universidad Carlos III de Madrid}

EN SEPTIEMBRE DE 2012, CUANDO DISFRUTABA DE UNA ESTANCIA como investigador postdoctoral en la Universidad Carlos III de Madrid, el autor de este trabajo comenzó la andadura nada fácil de examinar el texto que estudia y edita en este libro: la peregrinación a La Meca de un mudéjar castellano, Omar Paton. Su larga experiencia investigadora, junto a su condición de experto en aljamía, le han permitido editar el texto de la peregrinación, precedido de un magnífico estudio de todo lo que rodea al escrito de Paton, estudio que permite una mejor comprensión del texto editado, pero que, además, tiene gran valor por si mismo, al dar a conocer en profundidad un aspecto tan importante para entender la religión islámica como es la peregrinación a La Meca. 
El libro está muy bien estructurado. Se divide en tres grandes partes: la primera se ocupa de los "estudios sobre la obra" (pp. 15-269), la segunda de la edición del texto, y la tercera de un glosario. Cumple bien los objetivos que se propone el autor: dar una buena explicación del Memorial de ida i venida hasta Maka en el que Omar Paton, mudéjar de Ávila, expone "vivencias, impresiones y emociones acumuladas durante cinco largos años de trayecto por el Mediterráneo y Oriente”. No se puede más que estar de acuerdo con las palabras de Pablo Roza cuando apunta la "excepcionalidad del relato autobiográfico" del mudéjar abulense, y su importancia como "testimonio de primera mano para el conocimiento de la época en sus más diversos aspectos: históricos, políticos, económicos, religiosos, etc.”.

Bajo el título "estudios sobre la obra" cabría esperar una exposición del estado de la cuestión sobre la obra de Omar Paton, sin embargo, esta parte del libro va mucho más allá. Empieza el autor explicando la peregrinación entre mudéjares y moriscos, con una exposición de los antecedentes y del contexto socio-religioso. Como antecedentes toma el tiempo de dominio de Al Andalus. Siendo la peregrinación a La Meca uno de los cinco pilares del Islam, es lógico preguntarse cómo podían cumplir con ese precepto los musulmanes que vivían en el extremo del Mediterráneo más alejado de la ciudad santa de La Meca. Hay una clara explicación: la peregrinación estaba limitada a los grupos con más poder adquisitivo, y fundamentalmente a los varones. Además, otro aspecto podía influir en el ánimo de iniciar el viaje: la posición, más o menos favorable a la peregrinación, de los gobernantes de las distintas fuerzas que controlaron el territorio hispano desde la llegada de los árabes. Es interesante observar la postura de los dirigentes de Al Andalus (omeyas, almorávides y almohades), que ni impidieron ni favorecieron los viajes para cumplir el precepto, pero que no fueron entusiastas. Sus razones para la falta de entusiasmo fueron de índole ideológica, pues temían el contagio de "novedades e innovaciones, vistas como un peligroso bagaje con el que el viajero podía regresar tras una prolongada estancia en tierras extranjeras”. Así pues, por unas razones u otras, ni siquiera en la etapa de dominio territorial de la península por parte de los árabes, no era común la peregrinación de los habitantes de Al Andalus, como tampoco lo fue cuando vivieron bajo el dominio de los reinos hispánicos, en las etapas mudéjar y morisca. Esta parte del estudio, es decir, la exposición de la costumbre del viaje a La Meca, permite entender muy bien la "excepcionalidad" del viaje de Omar Paton. Sin conocer el contexto socio-religioso de finales de la Edad Media, no podría entenderse el viaje de peregrinación de este vecino de Ávila.

El primer apartado de la primera parte del libro cuenta con otros dos sub-apartados que son especialmente importantes, pues analizan las fuentes de información sobre los viajes de peregrinación. En primer lugar, el autor estudia los textos aljamiados de diversa índole (textos de jurisprudencia, de amonestación, de exiliados, etc.), y en segundo lugar los relatos de viajeros mudéjares y moriscos. Ambos tipos de fuentes permiten conocer de primera mano la época y las condiciones en las que en ese tiempo se podía cumplir con el quinto pilar del Islam.

El segundo gran apartado de la primera parte lo dedica el autor a la tradición manuscrita de la obra de Omar Paton. Este apartado es especialmente interesante para quienes se dedican a los estudios codicológicos. Pablo Roza hace un estudio de las copias aparecidas de la obra de Paton, escrita en caracteres latinos supuestamente. Las copias, en aljamiado, se hallaron una en Almonacid de la Sierra y otra en Calanda. Junto al interés del estudio codicoló- 
gico, algunos de los aspectos que el autor estudia sobre los manuscritos en aljamiado ayudan al historiador a entender aspectos muy interesantes de la vida del peregrino Omar Paton, así como la vida cultural de su tiempo, con una producción de libros en Castilla y Aragón, que pasaban de una corona a otra con gran trasiego. Una localidad del reino de Aragón, Calanda, destacaba por su papel cultural de creación de libros.

En el tercer gran apartado de la primera parte, Pablo Roza desmenuza detalladamente el Memorial de Omar Paton, y explica el significado de la peregrinación, la planificación y el desarrollo del viaje, el itinerario seguido, los peligros del camino, y los rituales al llegar a La Meca. Entre los méritos del trabajo se encuentra la exposición de puntos interesantes del viaje, con el complemento de elementos que enriquecen el escrito de Paton. Su viaje duró más de cinco años. Ante viajes tan duraderos, los viajeros tenían que buscar la forma de ganarse la vida, de ahí que, en la ruta a Oriente, Paton se encontrara con peregrinos procedentes de tierras hispanas ejerciendo oficios muy diversos. En realidad, todos y cada uno de los subapartados de esta parte son muy interesantes, buen ejemplo es el relacionado con los lugares de devoción que Paton visitó y en los que se detuvo. Uno de ellos fue Alejandría, en donde visitó la supuesta tumba de Alejandro Magno, de la que no solo da referencias Omar Paton sino que, como recoge Pablo Roza, otros autores posteriores apoyaron las creencias de Paton; uno de ellos fue León el Africano que apunta la pequeña construcción muy venerada por los musulmanes que se cree que es la tumba de Alejandro Magno; también en los planos de ciudades de Braun y Hogenberg se dibuja una pequeña construcción que se correspondería con la mezquita donde está la tumba de Alejandro que apunta Omar Paton. Junto a este lugar, que recuerda a uno de los personajes notables de la Antigüedad, llama también la atención el interés de los viajeros por pararse en lugares de tradición cristiana, en particular al pasar por Tierra Santa, lo que parece hacer de la peregrinación un paseo por la cultura mediterránea. Pablo Roza llama la atención sobre el conocimiento de las devociones cristianas con las que parecía estar familiarizado el viajero abulense; en efecto, Paton anota en su Memorial la visita a Jerusalén señalando expresamente los lugares que visitó, entre ellos el altar donde decía misa San Juan, y también la visita a Alejandría anotando la calle en la que ajusticiaron a San Marcos y las columnas donde asentaron la rueda del martirio de Santa Catalina. Interesante es también la referencia a los encuentros con algunas personas, con algunos comentarios bien significativos para el mundo de nuestros días. Dice Patón que, en Jerusalén, en la visita que efectuó al lugar del templo del rey David, se encontró con un fraile que era "era de España, del reino de Cataluña".

Llegado a La Meca, Paton, junto a un compañero de viaje, Corral, inicia los rituales propios de la peregrinación, que comenzaban con la llamada peregrinación menor. Paton expone en su Memorial, aunque de forma breve, los rituales tanto de la peregrinación menor como de la mayor, y demuestra que siguen los protocolos establecidos. El número 7, número sagrado, aparece en esos protocolos: el peregrino ha de dar 7 vueltas a la Kaaba con diferente intensidad, como también la intensidad varía en los 7 recorridos que han de efectuar en las afueras de la mezquita, de acuerdo con los rituales establecidos en el Corán. En algunos aspectos Paton sigue la tradición malikí, propia de los musulmanes andalusíes.

Entre los puntos que Pablo Roza señala en este estudio introductorio de la obra de Omar Paton, hay que indicar algunos relacionados con la cualidad del Memorial. Sin ser un 
tratado geográfico en sentido estricto, son interesantes las referencias que anota de carácter espacial, antropológico, económico de los lugares por los que pasa. Pero, además, con las anotaciones que realiza de sus gastos e ingresos, Paton proporciona una información muy valiosa acerca de los costes de vida en los países recorridos, concretamente en las ciudades por las que pasa. Sus descripciones de Damasco, El Cairo, Alejandría o La Meca, tienen interés para conocer aspectos muy diversos de esas ciudades, al tiempo que muestran la recepción clásica en la forma de elaborar esas descripciones, coincidentes con relatos cristianos, lo que lleva a Pablo Roza a apuntar la idea de Pérez Priego de sus orígenes en la "laudatio urbis de la retórica clásica”. Las coincidencias con la literatura cristiana quedan de manifiesto en el recurso a las maravillas que utiliza Paton, que coinciden con la literatura de las mirabilia cristianas de la etapa medieval. Pablo Roza concluye que el Memorial de Omar Paton "a caballo entre las obras de rihla andalusíes y los itineraria cristianos a Tierra Santa, supone una nueva muestra de la interconexión entre la literatura de unos y otros".

En la segunda parte del libro se encuentra una edición impecable y muy trabajada de la obra de Paton, con unas notas sobre el sistema de transliteración. La tercera parte consiste en un glosario en el que Pablo Roza ha incluido voces comunes, antropónimos, topónimos y frases y expresiones árabes, todo ello un aparato que muestra el nivel de trabajo científico que el autor ha puesto de manifiesto en este estudio.

El conjunto del libro representa, como se ha dicho arriba, una magnífica contribución al conocimiento de la peregrinación a La Meca de los musulmanes que habitaban en la península Ibérica. El hallazgo del Memorial es, sin duda, de gran importancia por lo que significa poder conocer de primera mano, aunque pasado por las manos de copistas, un documento como el de Omar Paton. Es este mudéjar de Ávila un buen representante de los individuos de procedencia urbana y nivel socio-económico medio que podían realizar el largo viaje a La Meca, largo por el espacio y por el tiempo que llevaba.

En el conjunto de estudios relacionados con el tema tratado en este libro, esta obra ocupa un lugar destacado. Con un lenguaje claro y sencillo, y con un estilo también claro al tiempo que elegante, el autor deja hablar a un musulmán abulense y a través de sus palabras, y del estudio de sus palabras, se consigue introducir al lector en la vida de un peregrino musulmán y entender bien el entorno que rodeaba el viaje de peregrinación. A ello contribuye la elección hecha por Pablo Roza de los puntos elegidos para explicar el viaje de Paton, uno de esos relatos que permite conocer sin intermediarios la realidad de un tiempo. Esta obra permite hacerse buena idea de lo que fueron los viajes a La Meca, en particular unos viajes tan largos para los mudéjares de Hispania. En resumen, hay que considerar este libro como una magnífica investigación, para lo que el autor ha desplegado sus dotes de buen conocedor de la aljamía, y de la bibliografía extensísima que ha utilizado en su trabajo. No se ha olvidado de apuntar los estudios que se han llevado a cabo sobre este tema al mismo tiempo que realizaba el suyo, buena muestra de un carácter humilde. 